\title{
A percepção do paciente amputado diante da mudança na imagem corporal
}

\section{The perception of the amputee patient in face of the change in body image}

\author{
Karine Costa Melo' • Francisca Tatiana Dourado Gonçalves ${ }^{2} \bullet$ Wenderson Costa da Silva ${ }^{3}$ \\ Alanna Nunes Soares ${ }^{4} \bullet$ Chrisllayne Oliveira da Silva ${ }^{5} \bullet$ Francisco das Chagas Araújo Sousa $^{6}$ \\ Maria Cristina Natasha Lima $\mathrm{Cruz}^{7} \bullet$ Elide Andressa de Andrade Rodrigues Severo ${ }^{8}$ \\ César Augusto Pereira Sousa Filho9 $\bullet$ Brunna Matos Sousa ${ }^{10} \bullet$ Layse Siqueira Costa Miranda $"$
}

\section{RESUMO}

Objetivo: avaliar a percepção do paciente amputado diante da mudança na imagem corporal. Métodos:Trata-se de uma pesquisa de campo, do tipo descritivo exploratória, transversal, com abordagem qualitativa, realizada em um hospital geral de um município do Maranhão, contando com uma amostragem de 09 participantes, de ambos os sexos. Resultados: Observou-se que há mudanças na percepção dos indivíduos acerca da imagem corporal após o processo de amputação, onde os principais sentimentos vivenciados pelos entrevistados foram tristeza, saudade do membro perdido, desesperança, insatisfação com a imagem corporal e intensa fragilização da mesma. Houve também diminuição do convívio social. Foi evidenciado ainda, que apenas três indivíduos apresentam resiliência quanto a sua situação atual, destacando a família como pilar para a superação de obstáculos enfrentados por eles. Conclusão: Diante desses problemas, fica claro que assistência prestada a estes indivíduos deve ser focada em aspectos físicos e emocionais. Nesse caso, a equipe de saúde deve entrar em ação lidando diretamente com o sujeito e prestando esclarecimentos acerca do procedimento realizado por ele, além de incentivar o uso de estratégias que busquem estimular o desenvolvimento de atividades voltadas para a reabilitação física e mental.

Palavras-chave: Enfermagem;Amputação; Sentimentos; Percepção.

\begin{abstract}
Objective: to assess the perception of the amputee patient in face of the change in body image. Methods:This is a field research, exploratory, cross-sectional, with a qualitative approach, carried out in a general hospital in a municipality in Maranhão, with a sample of 09 participants, of both sexes. Results: It was observed that there are changes in the perception of individuals about body image after the amputation process, where the main feelings experienced by the interviewees were sadness, longing for the lost limb, hopelessness, dissatisfaction with their body image and intense fragility. There was also a decrease in social interaction. It was also evidenced that only three individuals show resilience regarding their current situation, highlighting the family as a pillar for overcoming obstacles faced by them. Conclusion: In view of these problems, it is clear that assistance provided to these individuals should be focused on physical and emotional aspects. In this case, the health team must take action dealing directly with the subject and providing clarifications about the procedure performed by him, in addition to encouraging the use of strategies that seek to stimulate the development of activities aimed at physical and mental rehabilitation. Key words: Nursing;Amputation; Emotions; Perception.
\end{abstract}

\section{NOTA}

I Bacharel em enfermagem pelo Centro Universitário UNIFACEMA. Email: karinemelo09@gmail.com

2 Mestre em Saúde Coletiva pela Universidade Luterana do Brasil - ULBRA. Email: tatyanadourado@yahoo.com

3 Bacharel em enfermagem pelo Centro Universitário UNIFACEMA. Email: wendersocx09@gmail.com

4 Bacharel em enfermagem pelo Centro Universitário UNIFACEMA. Email: alanna_ns@hotmail.com

5 Bacharel em enfermagem pelo Centro Universitário UNIFACEMA. Email: chris-laynel0@hotmail.com

6 Doutor em Ciência Animal na área de Fisiologia da Reprodução pela Universidade Federal do Piauí. Email: franciscoaraujo@ccs.uespi.br

7 Discente do Curso de Psicologia pelo Centro Universitário UNIFACEMA. Email: nathashacris0@gmail.com

8 Bacharel em enfermagem pelo Centro Universitário UNIFACEMA. Email: elidesevero@gmail.com

9 Bacharel em enfermagem pelo Centro Universitário UNIFACEMA. Email: augustocesar_007@hotmail.com

I0 Bacharel em enfermagem pelo Centro Universitário UNIFACEMA. Email: brunnamattos4@gmail.com

I I Bacharel em enfermagem pelo Centro Universitário UNIFACEMA. Email:wendersoncx09@gmail.com 


\section{INTRODUÇÃO}

A amputação é definida como a retirada total ou parcial de um membro, que pode ocorrer devido a trauma ou realizada cirurgicamente, com um caráter reparador, devendo ser vista como continuação de um tratamento e não isoladamente, sendo utilizada para tratar complicações de várias doenças. Com o objetivo de melhorar a qualidade de vida do paciente, o cirurgião realiza uma estratégia cirúrgica que antecipa um regime de reabilitação, porém, para isso o cliente necessita ter um acompanhamento efetivo da equipe multiprofissional ${ }^{(1)}$.

Somente em dezembro de 2017 foram realizadas 87. 128,28 cirurgias para amputação de membros superiores em todo o território nacional ${ }^{(2)}$, e um total de 2.680.8II,20 internações hospitalares em 20I7, incluindo internações para realizar amputações de membros no Estado do Maranhão(3). É sabido, ainda, que pacientes acometidos pelo diabetes têm risco aumentado para a realização do procedimento, pois estudos realizados mostram que as principais causas de amputações se relacionam a doenças vasculares, processos infecciosos, e complicações decorrentes do diabetes ${ }^{(4)}$.

Observa-se que, após a amputação, os pacientes passam a apresentar um conjunto de mudanças não só físicas, como psicológicas e sociais. É notado o impacto do procedimento ao nível da imagem corporal que, geralmente, modifica a forma como o indivíduo olha para o próprio corpo. E ainda interfere, de forma acentuada, no ajustamento psicossocial do cliente, que se relaciona com uma baixa na sua autoestima, podendo ocasionar o surgimento de uma sintomatologia psicopatológica e prejudicar seu funcionamento social ${ }^{(5)}$.

Diante do exposto, apresenta-se a necessidade de avaliar a percepção do cliente diante da mudança corporal por ele sofrida, dando ênfase aos sentimentos relatados por ele e identificando os principais impactos físicos e psicológicos causados pelo procedimento em sua vida. Desta forma, a escolha da temática teve início a partir da necessidade de se compreender a percepção do paciente diante das mudanças provocadas pela amputação e suas consequências, os sentimentos relatados por eles e os principais impactos causados pelo procedimento em sua vida.

Este estudo teve como problemática "Qual a percepção do paciente amputado diante da mudança na imagem corporal?". Para tal, objetivou-se avaliar a percepção do paciente amputado diante da mudança na imagem corporal, mais especificamente, relatar a representação mental que o paciente tem do próprio corpo após o processo de amputação; descrever os principais sentimentos relatados pelo paciente em relação à imagem corporal após o processo de retirada de um membro e identificar os impactos sociais relacionados à amputação.

\section{MÉTODOS}

O estudo refere-se a uma pesquisa de campo, do tipo descritivo exploratória, transversal, com abordagem quanti-qualitativa.

A pesquisa foi realizada em um hospital geral de um município do Maranhão, onde este foi escolhido por se tratar de um hospital que atende pacientes com diversas patologias, e oferece atendimentos especializados em diferentes áreas como: clínica cirúrgica geral, cardiologia, enfermagem, fisioterapia, entre outros, que o tornam referência em atendimentos para a população da cidade, recebendo um grande fluxo de pacientes e se caracterizando como um local muito apropriado para coletar dados sobre pacientes e casos clínicos diferenciados, possibilitando o desenvolvimento de pesquisas em diversas áreas.

O estudo foi realizado em um hospital geral de um município do Maranhão, onde este forneceu dados sobre os pacientes que passaram por amputações nos últimos seis anos, e os dados foram utilizados para contatá-los. Assim, estiveram aptos para participar da pesquisa, pacientes com excisão de qualquer componente corporal.

Como critérios de inclusão para participação na pesquisa foram selecionados indivíduos com idade entre 18 e 82 anos, que realizaram amputação em até seis anos, e que receberam assistência hospitalar no município. Quanto aos critérios de exclusão, não estiveram aptos para o estudo pessoas com idade inferior a 18 anos, ou que apresentaram distúrbios mentais que as impeça de responder por si mesmas, e ainda, indivíduos que não tiveram disponibilidade de tempo para responder as perguntas da entrevista.

Foram selecionados 15 pacientes que se enquadravam no perfil, dos quais, três não quiseram participar, dois não foram localizados, e um desistiu de realizar a entrevista. Ao final, a pesquisa contou com a amostragem de nove participantes do sexo feminino e masculino e usou critério de saturação. Estes foram selecionados com a amostragem aleatória simples sem reposição.

O recurso utilizado para coletar os dados foi a aplicação de um questionário formado por duas partes, de modo que a primeira compunha um questionário com informações sociodemográficas do indivíduo, e a segunda caracterizava uma entrevista com perguntas abertas acerca do tema proposto, permitindo que o paciente se expressasse mais livremente. Para isso, o questionário e a entrevista foram realizados individualmente, e as respostas foram anotadas e gravadas (com a autorização prévia do paciente) para posterior reprodução, análise qualitativa e interpretação. Outro ponto importante foi a observação das expressões e comportamentos dos clientes durante o encontro.

Depois do processo de seleção, os pacientes foram 
procurados e receberam um convite verbal para participar da pesquisa. A seguir, um termo de consentimento livre e esclarecido (TCLE) foi disponibilizado e assinado por aqueles que se dispuseram a participar do estudo. O termo seguiu as normas da Resolução $n^{\circ} 466 / 12$ do Conselho Nacional de Saúde (CNS) sobre as pesquisas que envolvem seres humanos. Ressalta-se, aliás, que a identidade do paciente foi mantida em sigilo profissional.

O período da coleta dos dados ocorreu entre os meses de março e abril de 2019, e as entrevistas tiveram duração média de 30 a 40 minutos. Quanto às perguntas do questionário, estas serviram como norteadoras para guiar a entrevista, servindo como base para avaliar a percepção dos pacientes diante da sua nova imagem corporal, e promovendo a avaliação dos principais sentimentos relatados por eles.

Este projeto de pesquisa foi submetido à plataforma Brasil e encaminhado ao Comitê de Ética em Pesquisa do Centro universitário de Ciências e Tecnologia do Maranhão - UNIFACEMA. Tendo visto que, os pesquisadores foram os responsáveis por cumprir todas as normas que são preestabelecidas na Resolução CNS n 466/I2, que dispõe sobre a proteção aos participantes das pesquisas científicas envolvendo seres humanos, sob o $\mathrm{n}^{\circ}$ de Certificado de Apresentação para Apreciação Ética (CAAE) $n^{\circ}$ 09463019.4 .0000 .8007$.

\section{RESULTADOS E DISCUSSÃO}

A apresentação dos resultados e discussão foi estruturada em duas etapas: Onde a primeira refere-se à caracterização dos sujeitos que participaram da pesquisa, e a segunda diz respeito ao cumprimento dos objetivos do estudo mediante a exposição e análise dos depoimentos dos participantes.

A aplicação do instrumento de coleta de dados possibilitou a caracterização dos participantes da pesquisa, abordando variáveis sociodemográficas que incluíram sexo, idade, estado civil, religião, escolaridade, profissão e situação socioeconômica.

A amostra foi constituída por nove participantes que passaram pelo processo de amputação nos últimos seis anos, onde destes, seis (67\%) eram do sexo masculino e três (33\%) eram do sexo feminino. No que diz respeito à faixa etária dos participantes, a idade variou entre 28 e 82 anos, destes, três (33\%) apresentaram idades entre 28 e 55 anos e seis $(67 \%)$ possuíam idades entre 59 e 82 anos.

Em relação ao estado civil, quatro $(45 \%)$ entrevistados eram casados, três (33\%) viúvos e dois $(22 \%)$ solteiros. No que concerne à religião, dois (22\%) participantes eram protestantes e sete $(78 \%)$ eram católicos. Já na escolaridade quatro (45\%) pessoas possuíam ensino fundamental, três ( $33 \%$ ) ensino médio, uma (1 I\%) pessoa possuía ensino superior e uma (I I\%) nunca frequentou a escola.

Quando perguntados sobre a profissão houve predominância de indivíduos aposentados, onde quatro (45\%) sujeitos relataram receber a aposentadoria, três (33\%) lavradores, uma (I I\%) professora e um (I I\%) mecânico. No que diz respeito às condições socioeconômicas, quatro (45\%) indivíduos disseram que as suas condições são regulares, três (33\%) pessoas relatam ter boas condições, e dois $(22 \%)$ sujeitos caracterizaram suas condições socioeconômicas como ruins.

\section{AS CLASSES E SUAS DESCRIÇÕES}

As informações foram adquiridas por meio de entrevistas com pacientes que passaram pelo processo de amputação de um componente corporal nos últimos seis anos, onde os dados pertinentes ao estudo foram expostos mediante as falas dos indivíduos, com total garantia de anonimato, para isso, os sujeitos foram identificados apenas com o nome "Participante" e por números que designaram a ordem na qual as entrevistas foram realizadas (Participante I, Participante 2, Participante 3...).

Para atingir os objetivos propostos pela pesquisa, a análise dos dados foi constituída de quatro classes: Classe I - A representação mental do próprio corpo após o processo de amputação; Classe 2 - Os principais sentimentos relatados após a amputação em relação à imagem corporal; Classe 3 - Impactos sociais relacionados à amputação; Classe 4 - Estratégias para aumentar a autoestima após o processo de amputação. As classes estão expostas a seguir descrevendo os principais resultados da pesquisa.

\section{CLASSE I.A REPRESENTAÇÃO MENTAL DO PRÓPRIO CORPO APÓS O PROCESSO DE AMPUTAÇÃO}

Sobre a representação mental do próprio corpo após o processo de amputação, dos nove indivíduos entrevistados, quatro sujeitos se mostraram tristes, descontentes e insatisfeitos com a imagem que têm de si mesmo, sendo evidenciados por choro fácil, expressões faciais de angústia e lamentação em relação à perda do membro. Em relação a esta perda, dois participantes exprimiram intensa fragilização quanto à sua imagem corporal, outros dois se mostram à margem da resiliência, e uma participante se descreve completa, negando a ausência do membro amputado, como revela as falas dos depoentes.

Na minha mente eu tenho uma imagem muito feia, só uma perna, diabetes é uma merda [...] não durmo a noite [...] (PARTICIPANTE 5). Eu imagino tristeza, quando me lembro que eu era tão forte, jogava bola, fazia vôlei, hoje só tristeza, eu não posso nem falar que já fico 
emocionado, pois é, só tristeza (choro) [...] (PARTICIPANTE 6).

Eu de primeiro me sentia saudável hoje em dia eu não sinto, depois que tirou minhas pernas eu fiquei triste comigo mesmo. Eu lembro do corpo de antes porque eu andava pra tudo que é lugar (choro) [...]. (PARTICIPANTE 7).

Após o processo de amputação muitos pacientes enfrentam dificuldades para se adaptar ao novo corpo, e sofrem uma intensificação dos seus sentimentos em relação ao membro perdido, dessa forma a imagem corporal é distorcida e o indivíduo se prende às lembranças do corpo completo, negando a sua realidade atual, como evidencia a fala da entrevistada:

Me vejo completa, eu vivi 60 anos completa, no ano passado perdi meus dedos, depois meu pé e agora corro risco de perda a perna (choro) [...] (PARTICIPANTE 2).

Enfrentar o processo de reabilitação após a amputação de um membro é um grande desafio para os sujeitos, pois a adaptação ao novo corpo provoca profundas alterações na autoimagem, fazendo com que o indivíduo, muitas vezes, vivencie sentimentos como tristeza e angústia, que pode se intensificar ainda mais, dependendo do tipo de estímulo que recebe das pessoas de seu ciclo social, onde sua percepção de autoimagem pode se tornar mais comprometida diante de opiniões negativas, ou ainda, se negar a ver o corpo de acordo com a nova realidade.

Frente a esses achados, estudos realizados por Bello e colaboradores ${ }^{(6)}$ afirmam que a experiência de amputar um membro é para a maioria dos pacientes, um processo triste e doloroso, no qual é vivenciado um sentimento de culpa por estar passando por aquela situação, medo e angústia. Porém, a intensidade dos sentimentos vivenciados varia de acordo com os valores individuais dos sujeitos, revelando ainda, que muitos indivíduos se sentem excluídos do convívio social por não conseguirem se locomover e não lidam de forma positiva com a dependência física que apresentam, tornando-se mais solitários e aumentando o desejo pelo membro perdido. Gerando uma visão distorcida do novo corpo, surge a baixa autoestima e sofrimento ${ }^{(7)}$.

Corroboram com a afirmativa, o estudo de Friggi e colaboradores $^{(8)}$ afirmam que $\circ$ processo de amputação ocasiona uma perda que não se restringe apenas ao corpo físico. As limitações que são impostas aos indivíduos provocam uma fragilização da imagem de si mesmo e redução do narcisismo, ou seja, do amor por si próprio, provocando consecutivos confrontos internos para o indivíduo, pois ele tenta se adaptar à nova realidade, mas o corpo de antes sempre vem à tona e se traduz nas atividades que o sujeito não pode dar continuidade ou não pode mais iniciar. Esta ausência faz com que o sujeito muitas vezes, não consiga se ver diante do espelho e não enfrente $\circ$ luto pelo membro perdido adequadamente ${ }^{(9)}$.

A falta que o indivíduo sente do membro perdido e o sentimento de impotência diante da situação, muitas vezes domina o sujeito, fazendo com que ele sinta desesperança e possa desenvolver episódios de choro, tristeza ou isolamento social, que podem ser comuns no início da fase de adaptação, porém, estes não podem ser vistos como algo normal e os indivíduos devem ser acompanhados por profissionais, a fim de evitar um agravamento do quadro e possível evolução para patologias.

Tá faltando uma perna né (choro) [...] (PARTICIPANTE I).

Tirou um pedaço, tem que faltar, faz falta e não tem jeito mesmo [...] (PARTICIPANTE 4).

Outro achado importante e que faz oposição a esta afirmativa, é a fala dos participantes que demonstraram resiliência em relação à situação atual, mostrando que existe divergência do significado do processo de amputação de acordo com a vivência de cada pessoa, e que muitas vezes o indivíduo enxerga a cirurgia como uma nova chance para viver de forma saudável.

Tá bom, porque eu não tô sentindo dor, tinha dias que eu via anoitecer e amanhecer, hoje estou sem minha mão, mas tou satisfeita sempre, antes os anéis ir e os dedos ficar, a gente com saúde é o melhor a base de Deus e nossa Senhora (PARTICIPANTE 3).

Tá sem meu pé, ficar com a perninha pequena, mas pra saúde da gente é o que importa né? A gente sem a perna da gente é ruim, mas Deus dar o jeito pra gente caminhar (PARTICIPANTE 8).

Segundo estudos de Santos e colaboradores ${ }^{(9)}$ a retirada do membro é um processo único e individual que muda drasticamente a vida do indivíduo e ocasiona o surgimento de muitos sentimentos que podem prejudicar o sujeito. Neste aspecto, o apoio da família e a religião influenciaram positivamente na adaptação do paciente, que demonstrou uma nova percepção da sua realidade e buscou adaptar-se à situação, retomando hábitos e atitudes. Há muitas vezes em que o indivíduo apresenta resiliência por compreender que o processo de retirada do membro foi a melhor opção para reestabelecer sua saúde ${ }^{(4)}$.

\section{CLASSE 2. SENTIMENTOS RELATADOS APÓS A AMPUTAÇÃO EM RELAÇÃO À IMAGEM CORPORAL}

Nesta classe, ficou evidenciado que após o processo de amputação, os pacientes experimentam sentimentos variados, no qual percorre as margens da resiliência e 
da negação, como culpa e arrependimento por não ter conseguido evitar o procedimento, ou ainda, forças para recomeçar, por estarem muitas vezes livres de dores, infecções, ou por não correr risco de vida no momento. Dentre os aspectos que envolvem a amputação, os indivíduos vivenciam sentimentos negativos em relação à sua imagem corporal, se manifestando principalmente em baixa autoestima, tristeza e saudade, como são evidenciados pela fala dos entrevistados:

Tive sentimento muito ruim, muito traumatizada, eu nunca pensei que eu ia ficar de cadeira de rodas, e simplesmente aconteceu [...]. Na minha mente eu tenho uma imagem muito feia [...] eu acho assim, a pessoa fica deficiente e muitas pessoas não dar mais valor, não presta atenção, tem até assim nojo [...] (PARTICIPANTE 5).

Meu pensamento é que tô vivendo só porque Deus quer mesmo, se fosse por mim eu já tinha ido embora [...] Eu lembro do corpo de antes porque eu andava pra tudo que é lugar (PARTICIPANTE 7)

Frente a esses achados, o estudo realizado por Fernandes e Barbosa ${ }^{(10)}$ afirmam que deformidades, amputações e defeitos físicos são formadores de corpos periféricos para os indivíduos, ou seja, o físico passa ser visto e sentido como oposto à beleza e aos padrões aceitos pela sociedade. Já que a imagem corporal é definida a partir das percepções físicas, cognitivas, afetivas e comportamentais, e se relacionam a fatores internos e externos, o impacto do processo de amputação resulta em profunda perturbação psicológica, pois o indivíduo precisa lidar com seus próprios sentimentos e as normas da sociedade na qual está inserido, provocando traumas e frustrações ${ }^{(11)}$.

O sujeito, muitas vezes, precisa de ajuda de outras pessoas para prover seu próprio cuidado e isso faz com que ele sinta que perdeu sua autonomia, sentindo vergonha do seu corpo, que não é mais considerado por ele como útil, completo, e ainda carrega cicatrizes da cirurgia. Isso faz com que o indivíduo perca a vontade de se ver no espelho e passe a evitar pensar na sua imagem física, pois esse pensamento muitas vezes lhe provoca tristeza.

Em um estudo realizado por Freysteinson e colaboradores $^{(12)} \mathrm{em}$ duas organizações de amputações na cidade de Houston, com amostragem de 22 indivíduos de ambos os sexos, mostrou que os sentimentos do indivíduo sobre o próprio corpo, ao se ver no espelho sem o membro amputado, geram uma grande angustia e seus sentimentos variam entre tristeza, medo, repulsão sobre o próprio corpo, ou ainda, desesperança e desânimo. Pois mesmo sabendo que a perda de um membro não é o fim da vida, muitos sujeitos acabam se tornando tristes e iso- lados, e como consequência podem desenvolver transtorno de ansiedade e depressão(13).

Embora seja evidente que após o processo de amputação os sujeitos enfrentem muitas dificuldades, e relatem problemas com sua imagem corporal, observouse também que muitas pessoas apresentam uma boa aceitação do novo corpo e assumem sua condição com resiliência, se apoiando na familia e amigos para seguir em frente, vendo sua nova condição como um recomeço, e não o fim da vida. Neste aspecto, as falas dos pacientes evidenciam que diante da perda de um membro, os sujeitos usam sua fé para explicar o fato ocorrido e ganhar forças para enfrentar as novas dificuldades e obstáculos, buscando formas de se distrair e evitar sentimentos de revolta.

Tô me distraindo mais porque eu sei que ela não vem mais, estou satisfeita, fiquei sem a mão, mas tô com saúde, a mão foi embora, mas a dor foi embora também, tá tudo bem graças a Deus [...] graças a Deus e Nossa Senhora tem pessoas que cuidam de mim e o povo me ajudando, pro modo de melhorar minha saúde. Se tiver oportunidade tem muitas lá que ajudam [...] (PARTICIPANTE 3).

Fiquei conformado porque graças a Deus que sarou. Não fiquei triste porque não tem jeito mesmo [...] (PARTICIPANTE 4).

Eu não tive sentimento, não tô triste, porque é mais antes tirar e ficar cuidando do que ficar daquele jeito. Foi Deus que conseguiu isso, é a vontade dele [...] (PARTICIPANTE 8)

Meu psicológico, graças a Deus eu mantive [...] (PARTICIPANTE 9).

Um estudo realizado em um centro de reabilitação de uma faculdade particular, com amostragem de doze pessoas por encontro, mostrou que estimular os pacientes a reforçar pensamentos positivos, os ajuda a diminuir a rejeição ao próprio $\operatorname{corpo}^{(7)}$. Como afirmam Pereira e colaboradores $^{(14)}$ em um estudo realizado em um departamento de Medicina Física e Reabilitação e um Centro de Reabilitação no norte de Portugal, com amostragem de sessenta e três sujeitos, a reabilitação física e psicológica dos pacientes está intimamente ligada à religião, aceitação, e humor, onde deve-se sempre levar em consideração o ambiente no qual o sujeito está inserido.

\section{CLASSE 3. IMPACTOS SOCIAIS RELACIONADOS À AMPUTAÇÃO}

Esta classe discorre sobre os impactos sociais vivenciados pelos participantes da pesquisa após o processo de amputação, no qual quatro participantes relataram ter bom convívio social, comentando terem muitos amigos, e que gostam de conversar, além de terem uma boa relação 
familiar, o que influencia positivamente na recuperação da sua rotina e, consequentemente, traz menos riscos de desenvolverem transtornos psicológicos.

Tenho muitos amigos, gosto de conversar [...] (PARTICIPANTE I).

Tenho muitos amigos, recebo muita ajuda e estou satisfeita [...] Minha relação com meus filhos é boa porque mãe não tem carreira pro filho [...] (PARTICIPANTE 3).

Corrobora com esses achados, a pesquisa de Hawkins e colaboradores ${ }^{(15)}$ em um estudo realizado nos Estados Unidos, com 63 participantes que passaram pela cirurgia de amputação dos membros inferiores, na qual foi evidenciado que quanto maior o nível de interação social, maior é o nível de reabilitação do paciente, de modo que os indivíduos que tinham uma vida social ativa mostraram um aumento da qualidade de vida, pois o apoio de pessoas próximas promove uma maior aceitação da nova realidade do paciente. Diante disso, as falas e expressões faciais dos indivíduos não demostraram raiva ou tristeza, mas sim, expressões suaves e bom humor, chegando a fazer piadas com o fato ocorrido.

Dos indivíduos entrevistados, cinco indivíduos declararam ter diminuído seu convívio social após o processo de amputação ou ainda, que os amigos deixaram de aparecer devido a sentimentos de asco em relação a eles, ou por conta de não exercerem mais nenhuma atividade, 0 que evidencia os pensamentos que eles próprios tem em relação a si mesmos.

Eu só da cama para a cadeira de roda, da cadeira de roda para a cama, e pronto! eu não sento em uma cadeira, nem no sofá da casa [...] eu encosto na sala, quando encostam comigo e só foi umas duas vezes, aliás, no Natal, Ano Novo, e a uns vinte dias, eu pedi e me colocaram [...] (PARTICIPANTE 2).

Meu número de amigos diminuiu, eu não sei porque, eu acho assim, a pessoa fica deficiente e muitas pessoas não dar mais valor, não presta atenção, tem até assim nojo, não gosta de ficar perto, mas eu sou uma pessoa lavadinha, eu me lavo e me banho direitinho e tudo [...] (PARTICIPANTE 5).

De começo tinha muitos amigos, hoje em dia não aparece um pra mim dar um pão. É porque eu não tô mais trabalhando, eu não tenho atividade, eu não saio, só fico aqui [...] (PARTICIPANTE 7).

Diante da fala dos pacientes, é observado que eles muitas vezes são esquecidos pelos amigos, ou ainda que, a família preocupa-se apenas em prover cuidados físicos, o que contribui para o isolamento destes indivíduos, que muitas vezes sentem não serem mais úteis e necessários, e os leva a crer que suas limitações provocam nojo e afastamento das pessoas.

Corrobora com esses achados, o estudo de Santos e colaboradores ${ }^{(9)}$ realizado com dez usuários dos serviços de reabilitação do município de Bagé (RS), onde estes afirmaram ser tristes, ressentidos e nervosos, vivenciando principalmente um sentimento de abandono por não terem conseguido manter suas amizades em decorrência da mudança em suas rotinas. Neste aspecto, torna-se claro que a adaptação do sujeito ao processo de amputação pode ser influenciada, de forma positiva ou negativa, a depender dos estímulos sociais que lhe são ofertados ${ }^{(11)}$.

\section{CLASSE 4. ESTRATÉGIAS PARA DESENVOLVER A AUTOESTIMA APÓS O PROCESSO DE AMPUTAÇÃO}

Sobre a autoestima dos entrevistados e estratégias realizadas por eles para aumentá-la, foi observado que após o processo de amputação de um membro, os indivíduos têm sua autoestima rebaixada em menor ou maior grau. Diante disso, as falas dos entrevistados demonstram que eles, independentemente de serem tristes ou resilientes, não praticam atividades que visem manter ou aumentar sua autoestima. Apesar de quatro indivíduos afirmarem ter convívio social ativo, somente dois deles consideraram que praticam estratégias para aumentar sua autoestima, o que torna os que não praticam, ainda mais desgostosos e, consequentemente, reflete na sua autoimagem e gera uma diminuição da autoestima dos mesmos.

A minha estratégia é ter muitos amigos, gosto de conversar [...] (PARTICIPANTE I).

Só mesmo estudando a bíblia, orando 3 horas da madrugada e ao meio dia, para Deus tem que agradecer, estou esperando uma perna, ou uma cadeira de rodas para voltar a frequentar a igreja [...] (PARTICIPANTE 5).

Estratégias para manter ou aumentar a autoestima são fundamentais para a recuperação do indivíduo que passou pelo processo de amputação de um componente corporal, se fazendo necessário o apoio da família e amigos, além de um acompanhamento profissional. Neste aspecto é notado que dois dos sujeitos da pesquisa adotaram métodos que influenciam positivamente na sua saúde, porém, essas estratégias estão sendo utilizados isoladamente e eles não são acompanhados por psicólogos nem outros profissionais, o que diminui a eficácia das mesmas, onde apesar de os entrevistados declararem ter estratégias para aumentar sua autoestima, os mesmos se mostraram tristes, preocupados e desmotivados.

Corrobora com a afirmativa, o estudo de Mata, Souza e Rodrigues ${ }^{(16)}$, no qual foi observado que, quanto o maior grau de conhecimento e de acompanhamento 
multidisciplinar ao paciente, maior a eficácia das estratégias de cuidados com a saúde, onde a prática de esportes ganhou destaque, tanto na reabilitação física dos indivíduos quanto na melhora da percepção da autoimagem e aumento da autoestima. Os estímulos físicos fazem os pacientes perceberem que são capazes de superar suas limitações e até mesmo desenvolver novas atividades. Neste sentido, outra estratégia que mostrou resultados, foi a dançaterapia, onde a interação social dos sujeitos aumentou, além de mostrarem aumento da autoestima, provocando efeitos positivos na reabilitação dos indivíduos ${ }^{(17)}$.

Eu fico em cima da cama, quando muito eu sento e assisto televisão, que não assisto, só ouço, e hoje em dia eu tô aqui, esse trapinho [...] (PARTICIPANTE 2).

Vivo emocionado, tem umas pessoas que chega e fala que eu estou muito magro, pergunta $o$ que tá acontecendo, quer dizer, tá me derrubando mais [...] (PARTICIPANTE 6).

Não tenho como, não faço nada, mas eu tenho vontade de ocupar minha mente em alguma coisa [...] (PARTICIPANTE 7).

A sensação de abandono é expressa pelos entrevistados tanto nas suas falas quanto nas suas expressões corporais e faciais, de forma que, a todo o momento, os indivíduos se mostravam cabisbaixos, tiveram choro fácil, estavam tristes e desaminados. Outro ponto importante relatado foi o desejo de realizar alguma atividade, porém eles se sentiam incapazes porque apresentavam dependência física de outras pessoas. Com todos esses sentimentos negativos, a autoestima dos sujeitos se mostrou comprometida, já que eles muitas vezes não têm uma imagem positiva em relação ao seu corpo, se consideram inaptos para exercer atividades físicas e ainda tem que lidar com comentários negativos acerca da sua aparência.

Corrobora com essa afirmativa, o estudo realizado por Pereira e Braga ${ }^{(18)}$, com quatro pacientes que foram submetidas ao processo de amputação, onde os mesmos foram entrevistados e constatou-se que a autoimagem é influenciada pela opinião das outras pessoas, portanto, a autoestima pode ser diminuída de acordo com os estímulos que outras pessoas dão ao sujeito. Frequentemente, os sujeitos que passam pela adaptação ao novo corpo têm sentimentos de autopiedade, tristeza e autoestima diminuída ${ }^{(19)}$.

Diante disso, fica claro que fatores individuais são suportes para evidenciar a atitude dos sujeitos perante novas situações, portanto, não se pode prever o posicionamento do paciente após o processo de amputação de um membro corporal, no entanto, a assistência prestada a estes sujeitos deve ter em vista manter e/ou aumentar sua autoestima e reduzir estresses desnecessários, a fim de minimizar o risco de psicopatologias relacionadas à autoestima e autoimagem ${ }^{(20)}$.

\section{CONCLUSÃO}

Este estudo permitiu observar a percepção dos indivíduos acerca das mudanças na imagem corporal após o processo de amputação, onde os principais sentimentos vivenciados pelos entrevistados foi tristeza, saudade do membro perdido, desesperança, insatisfação com a imagem corporal e intensa fragilização. Houve também diminuição do convívio social, pois os sujeitos relataram que o número de amigos diminuiu. Foi evidenciado ainda, que apenas três indivíduos apresentam resiliência quanto a sua situação atual.

Diante dos problemas encontrados, fica claro que assistência prestada a estes indivíduos deve ser focada em aspectos físicos e emocionais. Nesse caso, a equipe de saúde deve entrar em ação lidando diretamente com o sujeito e prestando esclarecimentos acerca do procedimento realizado por ele, além de incentivar o uso de estratégias que busquem estimular o desenvolvimento de atividades voltadas para a reabilitação física e mental, sempre priorizando as queixas dos pacientes.

Já que a enfermagem exerce importante papel para a reabilitação dos pacientes amputados, e é um elo direto entre o sujeito e os demais profissionais de saúde, os enfermeiros devem avaliar a qualidade da assistência prestada, estendendo o tratamento além do âmbito hospitalar, encaminhando o paciente a outros profissionais (psicólogo, fisioterapeuta, nutricionista, etc.) sempre que houver necessidade, e monitorando o grau de conhecimento do indivíduo e da família acerca do seu tratamento.

Por fim, o estudo possibilitou expandir os conhecimentos acerca do processo de amputação e os sentimentos que são vivenciados pelos indivíduos diante da mudança na imagem corporal e na adaptação ao novo corpo. Dessa forma, considera-se que novas pesquisas devem ser realizadas nesta linha de investigação, a fim de provar a importância de cuidados multidisciplinares para uma completa readaptação do sujeito ao novo corpo. 


\section{REFERÊNCIAS}

I. Brasil. Ministério da Saúde. Diretrizes de atenção à pessoa amputada. [Internet]. Ministério da Saúde 2014 [acesso em II set 2018]. Disponível em: http://bvsms.saude.gov. br/bvs/publicacoes/diretrizes_atencao_pessoa_amputada_2edicao.pdf.

2. Brasil. Ministério da Saúde. Procedimentos hospitalares do SUS - por local de internação [Internet]. Ministério da Saúde 2018 [acesso em 12 set 20l8]. Disponível em: http:// tabnet.datasus.gov.br/cgi/deftohtm.exe?sih/cnv/qiuf.def.

3. Brasil. Ministério da Saúde. Morbidade hospitalar do SUS por causas externas [Internet]. Ministério da saúde 2019 [acesso em II jun 2019]. Disponível em: http://tabnet.datasus.gov.br/cgi/tabcgi.exe?sih/cnv/fiMA.def.

4. Marques AMFB, Vargas MAOI, Schoeller SD, Kinoshita EY, Ramos FRS, Trombetta AP. O cuidado à saúde à pessoa com amputação: análise na perspectiva da bioética. Texto contexto - enferm [Internet]. 2014 [acesso em 20 ago 2018]; 23(4):898-906. Disponível em: http://www.scielo.br/scielo.php?script=sci_arttext\&pi$d=S 0$ I 04-070720 I 4000400898\&Ing=en.

5. Silva MS.A imagem corporal na amputação: Relação com a depressão, a ansiedade, a satisfação com o suporte social e a autoestima global [dissertação]. Porto: Faculdade de Psicologia e de Ciências da Educação da Universidade do Porto; 2013.

6. Bello EF, Souza EM, Comassetto I, Oliveira JM. Vivência do idoso institucionalizado com membros inferiores amputados decorrentes de complicações do diabetes mellitus. Rev. Enfermagem UFPE [Internet]. 2014 [acesso em 16 abr 2019]; 8(I):44-5I. Disponível em: https://pesquisa.bvsalud. org/portal/resource/pt/biblio-915375.

7. Reis AH, Schwab JÁ, Neufeld CB. Relato de experiência de Terapia Cognitivo Comportamental em Grupo com pacientes amputados. Rev. Brasileira de Terapia Comportamental e Cognitiva [Internet]. 2014 [acesso em 3 mai 2019]; I 5(2): |48- I64, 2 I. Disponível em: http://www.usp.br /rbtcc/index.php/RBTCC/article/view/695.

8. Friggi PF, Quintana AM, Reis CGC Dos, Farias CP. A reconstrução dos contornos do eu: um olhar psicanalítico sobre a amputação. Psicologia em Pesquisa [Internet]. 2018 [acesso em 3 mai 2019]; 12(I):63-72. Disponível em: http:// pepsic.bvsalud.org/scielo.php?script=sci_abstract\&pi$d=S \mid$ 982- $|24720| 8000|00008 \&| n g=p t \& n r m=i s o$.

9. Santos CP dos, Escobal APL, Strefling ISS, Vargas E de, Vaz CHGJ, Vargas BC de. Reconstrução da identidade da pessoa amputada. Rev. Da jornada de Pós-Graduação e pesquisa [Internet]. 2018 [acesso em 5 out 2019]; I 5: 523-534. Disponível em: http://ediurcamp.urcamp.edu.br/index. php/ rcjpgp/article/view/2838/I 947.

I0. Fernandes L, Barbosa R. A construção social dos corpos periféricos. Saude soc [Internet]. 2016 [acesso em I 3 mai 2019]; 25(I):70-82. Disponível em: http://www.scielo.br/
scielo.php?pid=S0 I 04- $\mid 29020$ I 6000 I $00070 \&$ script $=$ sci abstract\&tlng=pt.

I I. Matos DR, Naves JF,Araujo TCCF.Ajustamento psicossocial de pessoas com amputação. Revista de Terapia Ocupacional da USP [Internet]. 2019 [acesso em I mai 2019];29(3):288292. Disponível em: https://www.revistas.usp.br/rto/article/ view/l 45426.

12. Freysteinson WN, Thomas L, Sebastian-Deutsch A, Douglas D, Melton D, Celia T, et al. Um estudo da experiência do amputado de ver o eu no espelho. Rev. Enfermagem de Reabilitação [Internet]. 2017 [acesso em 3 mai 2019]; 42(I):22-32. Disponível em: https://www.ncbi.nlm.nih.gov/ pmc/articles/PMC5228627/.

13. Sousa AC, Morais JC, Rêgo LTA. O processo do constructo da estrutura psicológica e dos mecanismos de enfrentamento do indivíduo que é acometido pela amputação de um membro e conquista a superação. Rev. Psicologado [internet] 2014 [acesso em 3 mai 2019]. Disponível em: https://psicologado.com.br/abordagens/psicologia-cognitiva/o-processo-do-constructo-da-estrutura-psicologica-edos-mecanismos-de-enfrentamento-do-individuo-que-e-acometido-pela-amputacao-de-um-membro-e-conquista-asuperacao.

14. Perreira GM, Ramos C, Lobarinhas A, Machado JC, Pedras S. Satisfação com a vida em indivíduos com amputação de membros inferiores: a importância do enfrentamento e aceitação ativos. Scandinavian Journal of Psychology [Internet]. 2018 [acesso em 4 mai 2019]; 59(4): 4I4-42I. Disponível em: https://onlinelibrary.wiley.com/doi/abs/I0.1 I I I/ sjop. 12444.

15. Hawkins AT, Pallangyo AJ, Herman AM, Schaumeier MJ, Smith AD, Hevelone ND, et al. O efeito da integração social nos resultados após a amputação de membros inferiores. Journal of Vascular Surgery [Internet]. 2016 [acesso em 6 mai 2019]; 63(I):I54-I62. Disponível em: https:// www.ncbi.nlm.nih.gov/pmc/articles/PMC4739523/pdf/ nihms-730610.pdf.

16. Mata MS da, Souza AAF de, Rodrigues DS. Percepção da imagem corporal e da autoestima de atletas amputados. Rev. Científica UMC [Internet]. 2018 [acesso em 9 mai 2019]; 3(3):I-4. Disponível em: http://seer.umc.br/index. php/revistaumc/article/view/455/347.

17. Viriato RH, Hmeliowski NL, Nolasco DB, Sancinetti FP. Contribuições da dançaterapia no aspecto emocional de pessoas com deficiência física durante programa de reabilitação. Acta Fisiátrica [Internet]. 2014 [acesso em 10 mai 2019]; 2 I (2): 66-70. Disponível: http://www.revistas.usp.br/ acta fisiatrica/article/view/l03834.

18. Pereira D, Braga AAM.A mastectomia e a ressignificação do corpo no feminino. Revista Psicologia, Diversidade e Saúde [Internet]. 2016 [acesso em 27 ago 2018]; 5(1):47-64. Disponível em: https://www5.bahiana.edu.br /index.php/psicologia/article/view/60I. 
19. Barbosa LBA, Guerra CL, Resende JL, Andrade MBT de. Sentimentos e expectativas do ser-amputado: um olhar fenomenológico. Revista da universidade Vale do Rio Verde [Internet]. 2016 [acesso em 27 ago 2018]; I4(2):62-72. Disponível em: http://periodicos.unincor .br/index.php/revistaunincor/article/view/2605>.

20. Bergo MFC, Prebianchi HB. Aspectos emocionais presentes na vida de pacientes submetidos à amputação: uma revisão de literatura. Psicol. Teor. Prat [Internet]. 2018 [acesso em I3 mai 2019]; 20(1):47-60. Disponível em: http://pepsic.bvsalud.org/scielo.php?script=sci_arttext\&pi$d=S|5|$ 6-368720 | $8000|00003 \&| n g=p t \& n r m=i s o \& t \mid n g=p t$.

Recebido: 2020-04-26

Aceito: 2020-08-15 